\title{
Analisis Perbandingan Migrasi Metode Kirchhoff dan Migrasi Fx pada Data Seismik 2D Darat
}

Widya Susantia*, Okto Ivansyah ${ }^{\mathrm{b}}$, Muliadia, Bambang Avianthara ${ }^{\mathrm{c}}$

\author{
aProgram Studi Fisika, FMIPA Universitas Tanjungpura \\ Jalan Prof. Dr. Hadari Nawawi, Pontianak, Indonesia \\ bPoliteknik Negeri Pontianak \\ Jalan Jendral Ahmad Yani, Pontianak, Indonesia \\ cPT Elnusa Divisi Geosains Data Processing \\ Jalan Tb.Simatupang, Jakarta, Indonesia \\ *Email : widyasusanti54@gmail.com
}

\begin{abstract}
Abstrak
Telah dilakukan penelitian mengenai pengolahan data seismik 2D land menggunakan metode seismik dengan proses post stack migration dalam domain waktu dengan teknik migrasi kirchhoff dan migrasi fx untuk mengetahui hasil pencitraan bawah permukaan. Ketepatan dalam menggunakan teknik migrasi sangat diperlukan agar dapat mengakomodasi dan menghasilkan pencitraan dengan resolusi yang lebih baik dari sebuah data komplek. Tahap pengolahan data dilakukan sesuai dengan flow processing metode seismik. Dalam penelitian ini dilakukan variasi parameter nilai dip dan aperture. Untuk variasi parameter aperture yaitu 1000 ms, 2000 ms, 4000 ms, dan 6000 ms. Sedangkan variasi nilai dip yang dilakukan yaitu $15^{\circ}, 30^{\circ}, 45^{\circ}, 65^{\circ}$, dan $90^{\circ}$. Tahapan migrasi dilakukan dengan dua tahap yaitu migrasi kirchhoff dan migrasi fx. Hasil stack pada proses migrasi dengan teknik migrasi Kirchhoff menghasilkan pencitraan bawah permukaan terhadap kemungkinan suatu reflektor lebih kontinyu, akan tetapi tidak terlalu terfokus, sedangkan pada proses migrasi fx menghasilkan pencitraan reflektor yang lebih terfokus, lebih tegas dan lebih baik digunakan pada lapisan curam.
\end{abstract}

Kata Kunci : Post stack Migration, Fx Migration, Kirchhoff Migration

\section{Pendahuluan}

Eksplorasi terhadap sumber daya alam semakin intesif seiring meningkatnya permintaan sumber bahan bakar untuk sarana dalam berbagai hal, Maka dalam hal ini diperlukan suatu metode geofisika untuk mencari sumber energi tersebut salah satunya ialah memanfaatkan gelombang dengan metode seismik. Metode seismik merupakan salah satu bagian dari seismologi eksplorasi, dimana pengukuran dilakukan menggunakan sumber seismik sehingga terjadi gerakan gelombang di dalam medium dengan memenuhi hukum elastisitas ke segala arah dan mengalami pemantulan atau pembiasan akibat perbedaan kecepatan rambat gelombang. Survey seismik ini dilakukan untuk mendapatkan rekaman data seismik. Tahapan selanjutnya adalah melakukan pengolahan data pada rekaman seismik untuk menghasilkan penampang seismik dengan $\mathrm{S} / \mathrm{N}$ ratio yang tinggi tanpa mengubah kenampakankenampakan refleksi dengan kata lain meredam noise dan memperkuat sinyal [1]. Setiap tahapan dalam pengolahan data seismik dimaksudkan untuk meningkatkan resolusi data seismik[2]. Proses pengolahan data harus dilakukan dengan baik, tepat dan akurat agar dapat diinterpretasikan dengan tepat.
Salah satu tahapan dalam pengolahan data seismik adalah migrasi yang bertujuan untuk memindahkan reflektor seismik miring ke posisi yang sebenarnya pada penampang seismik [3], artinya memindahkan titik refleksi hasil perekaman ke titik reflektor sesungguhnya akibat difraksi. Migrasi data seismik adalah suatu proses pengolahan data seismik yang bertujuan untuk mengoreksi kesalahan penggambaran struktur geologi bawah permukaan akibat bidang reflektor tidak berada pada posisi yang sebenarnya [4]. Data rekaman hasil akuisisi lapangan merupakan pemantulan dari sinyal seismik terhadap lapisan bumi, jika ada lapisam miring akan membuat titik reflektor yang terekam bergeser pada posisi sebenarnya terlebih jika pada lapisan geologi bawah permukaan yang kompleks, maka untuk mengembalikan titik reflektor ke posisi sebenarnya dilakukan migrasi. Proses migrasi akan memindahkan reflektor miring relatif ke arah atas [5].

Migrasi dapat dilakukan dengan cara sebelum stack (pre-stack migration) dan sesudah stack (post-stack migration). Proses migrasi yang dilakukan setelah stack relatif lebih cepat dan efisien dalam pengolahan data seismik [6]. Metode migrasi dalam seismik yang digunakan adalah metode kirchhoff yaitu 
menjumlahkan amplitudo titik reflektor sepanjang lintasan lokasi sesungguhnya. Sedangkan metode $\mathrm{fx}$ migrasi adalah metode migrasi yang menggunakan pemanfaatan pemecahan gelombang yang dilakukan secara downward continuition. Berawal dari teori tersebut maka migrasi merupakan proses kontinuasi ke bawah. Teknik migrasi ini didasarkan pada penyelesaian persamaan diferensial gelombang [7].

\section{Metodologi}

Penelitian ini dilaksanakan di Bidang Pengolahan Data Seismik PT. Elnusa Tbk, Divisi GDP, Jakarta selama dua bulan terhitung dari tanggal 04 April s.d 30 Mei 2016 untuk pengolahan data dengan parameter akuisisi sebagai berikut :

Tabel 1. Parameter akuisisi data seismik

\begin{tabular}{cc}
\hline Informasi & Nilai \\
\hline Shoot point interval (m) & 60 \\
Geophone interval (m) & 30 \\
CDP Interval (m) & 15 \\
\hline
\end{tabular}

Data seismik yang direkam pada saat di lapangan selalu memiliki spesifikasi yang berbeda dengan yang digunakan dalam pengolahan standar seismik 2D, hal ini bergantung pada jenis dari akuisisi maupun daerah saat pengambilan data.

Dalam Penelitian migrasi seismik ini digunakan metode kirchhoff dan fx data darat (land) 2D. Mencakup tiga tahapan yaitu tahapan persiapan, tahapan pengolahan data, dan tahapan analisis. Jenis data merupakan data sekunder dan telah dilakukan picking kecepatan, residual statik, serta stacking yang diperoleh dari PT ELNUSA Geosains Jakarta. Perangkat pengolahan data yang digunakan adalah operating system linux sebagai basis kerja dengan Software perangkat lunak Geovecture plus 5.1 dari $C G G$, kemudian dilakukan migrasi pada metode kirchhoff dan $f x$. Adapun alur diagram penelitiannya sebagai berikut:

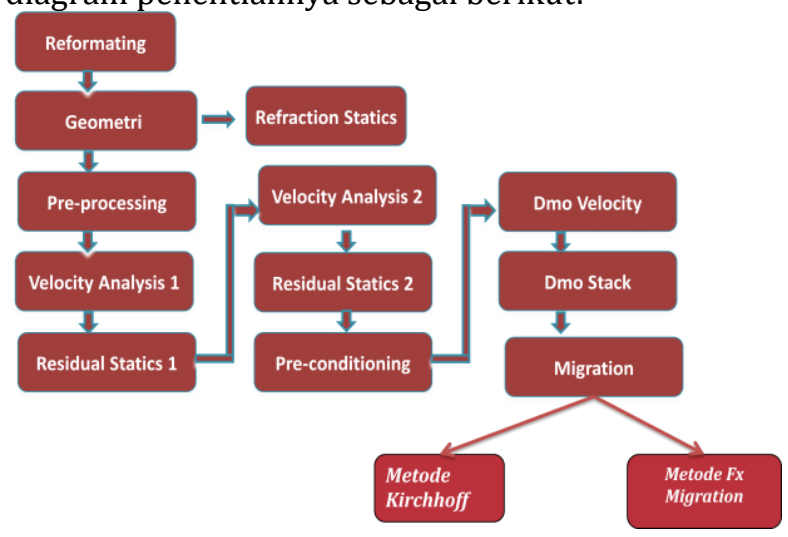

Gambar .1 Diagram Alir Tahapan Penelitian untuk analisis perbandingan metode migrasi

\section{Hasil dan Pembahasan}

Data yang digunakan adalah data stack Dip Move Out (DMO) karena DMO ini akan membuat hasil stack titik refleksi berubah, yaitu berada pada titik zero offset dari suatu reflektor, serta dilakukan koreksi terhadap lapisan miring dengan membuat trace seismik berada dalam Common Depth Point (CDP). DMO dilakukan Pada kasus lapisan miring, titik tengah pada stack tidak lagi merupakan proyeksi vertikal dari titik pantul, sehingga pada kasus lapisan miring, CDP gather tidak ekuivalen dengan CMP gather. Koreksi DMO dilakukan dengan cara mengeliminasi dip yang bergantung pada VNMO (Velocity Normal Move Out).

Penelitian ini dilakukan dalam domain waktu pada migrasi setelah stack (post stack time migration) dengan metode kirchhoff dan metode $\mathrm{fx}$ migration sebagai metode pembanding hasil migrasi. Parameter yang digunakan ialah tes dip, tes apperture, dan stacking velocity. Dalam penelitian ini ingin memperlihatkan migrasi aperture, nilai dip, dan stacking velocity yang akan mempengaruhi hasil migrasi. Secara teori, apabila menggunakan aperture secara optimal, maka akan didapatkan hasil penampang seismik yang lebih baik pula, oleh karena itu digunakan variasi aperture sebesar 1000 meter, 2000 meter, dan 6000 meter dengan dip $15^{\circ}, 30^{\circ}, 45^{\circ}, 65^{\circ}$, dan $90^{\circ}$. Serta stacking velocity $80 \%, 100 \%$, dan $120 \%$.

\subsection{Tes impuls pada aperture}

Aperture merupakan lebar data ke arah lateral yang akan ikut digunakan dalam penjumlahan titik-titik yang berada pada lintasan hiperbola akibat difraksi [8]. Penerapan nilai apperture yang bervariasi diperlukan dalam proes migrasi karena dengan demikian dapat diketahui nilai aperture yang optimum dan dapat memberikan hasil penampang yang baik untuk mempresentasikan bawah permukaan. Pemilihan nilai apperture yang digunakan penelitian ini diperoleh dari data geometri daerah penelitian. Pada penelitian ini akan dianalisis penampang hasil migrasi kirchhoff dengan variasi nilai migration aperture. Dimana telah dilakukan tes impuls terlebih dahulu yang dapat dilihat pada Gambar 2.

\subsection{Migrasi Metode Kirchhoff}

Migrasi Kirchhoff dip $45^{0}$ pada Gambar antara cdp 3920 - 4520 di kedalaman time $0 \mathrm{~ms}$ - 3000 ms,. Belum menghasilkan event-event seismik yang terlihat kemelurusan reflektornya. Untuk migrasi kirchhoff pada dip $65^{\circ}$ cdp 39204520 di kedalaman time $0 \mathrm{~ms}-3000 \mathrm{~ms}$, eventevent seismik dengan kemiringan yang curam 
masih terlihat kurang jelas kemelurusan reflektornya. Noise random dan noise ayunan yang curam semakin terlihat.

\subsection{Migrasi Metode Fx}

Pada dip $45^{\circ}$ terlihat bahwa event- event seismik sudah terlihat jelas pada kemiringan curam pada cdp 3920-4520 di kedalaman time 0 ms - 6000 ms. Dihasilkan fokus yang lebih baik. Noise random yang di hasilkan lebih banyak, akan tetapi noise ayunan yang terdapat tidak terlalu tampak. Sedangkan Hasil stacking dengan dip $65^{\circ}$ pada cdp 3920-4520 pada kedalaman time $0 \mathrm{~ms}-6000 \mathrm{~ms}$ tidak terdapat perubahan yang signifikan .akan tetapi eventevent seismik yang terlihat lebih jelas dan lebih teratur pola koherensinya. Noise yang dihasilkan juga sama dengan stacking pada dip $45^{\circ}$.

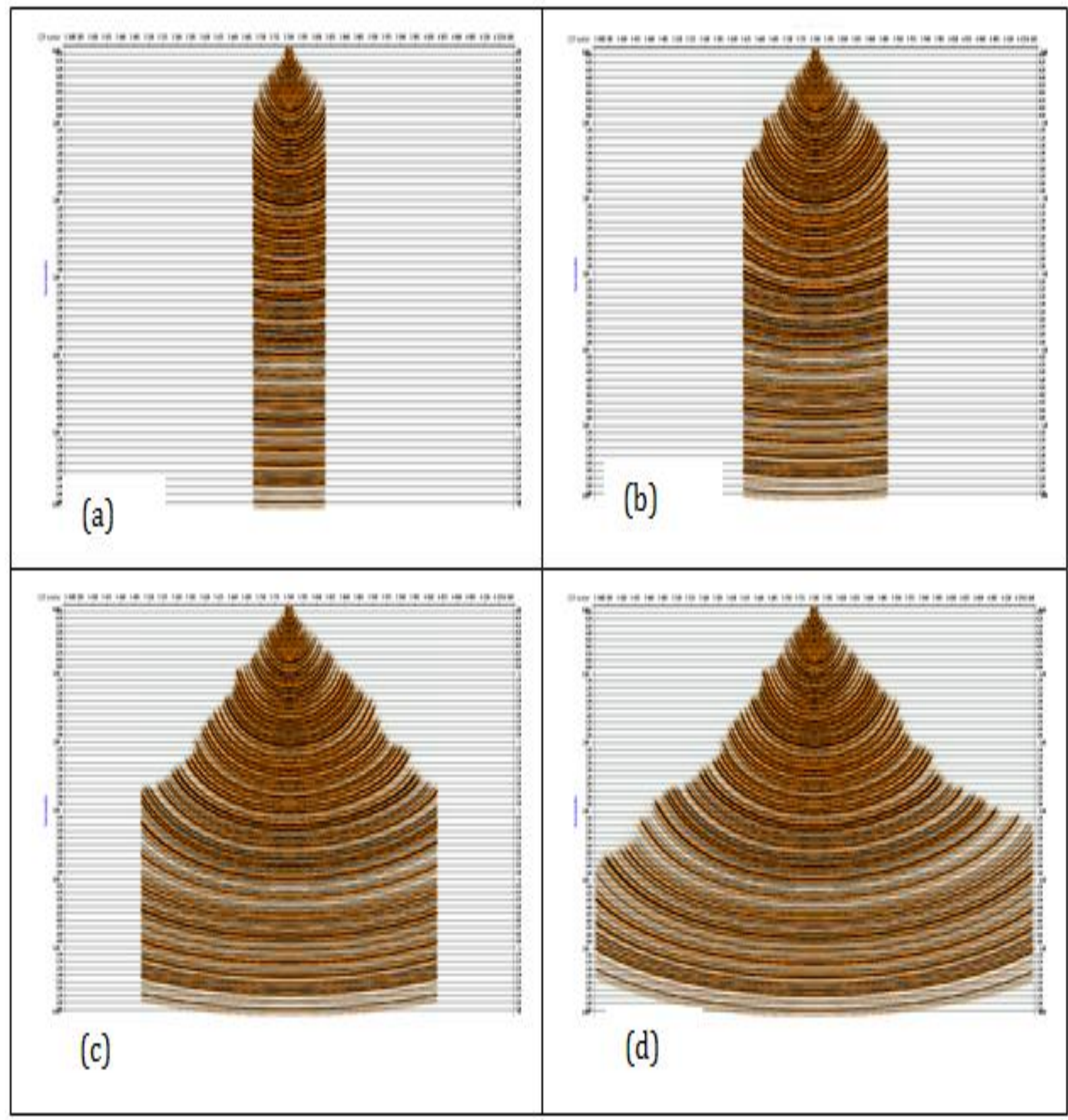

Gambar 2. (a) Tes aperture $1000 \mathrm{~m}$ pada impuls. (b)Tes aperture $2000 \mathrm{~m}$ pada impuls. (c)Tes aperture $4000 \mathrm{~m}$ pada impuls. (d)Tes aperture $6000 \mathrm{~m}$ pada impuls 


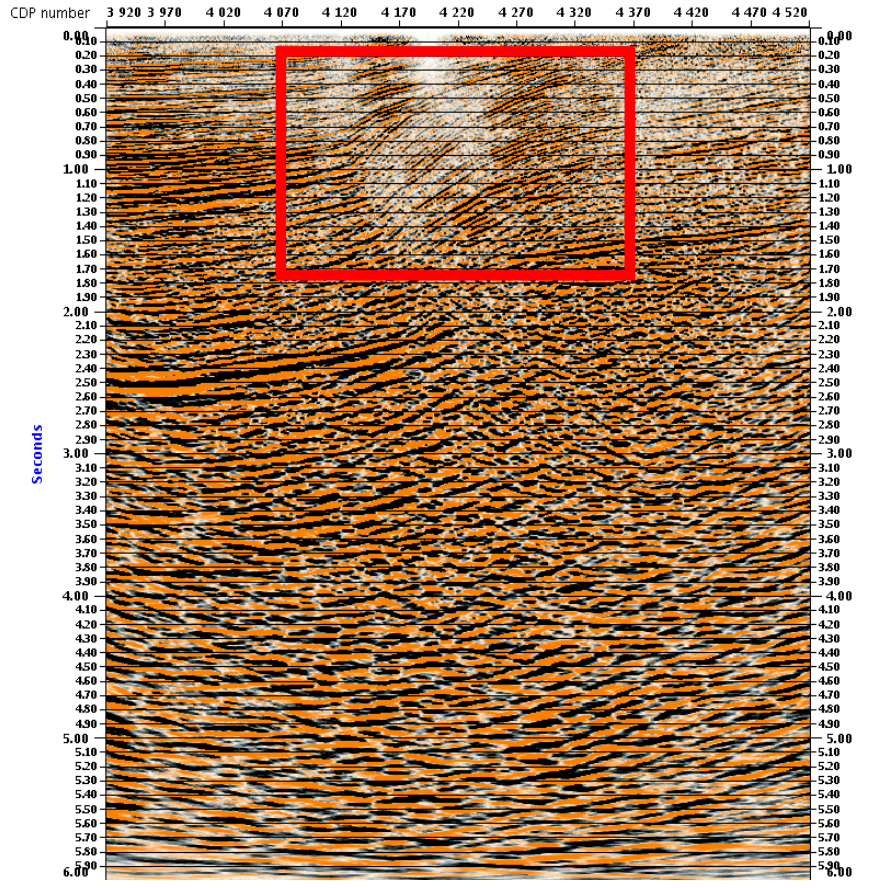

Gambar 3. Hasil stacking migrasi kirhhoff dip $45^{\circ}$

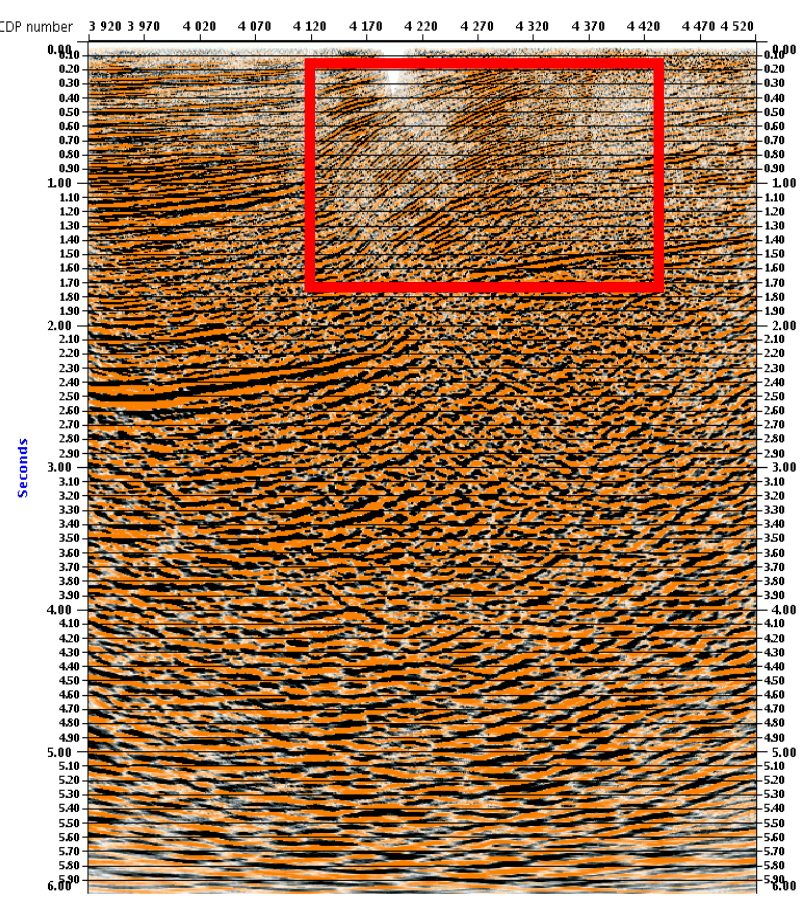

Gambar 4. Hasil stacking migrasi fx dip $45^{0}$

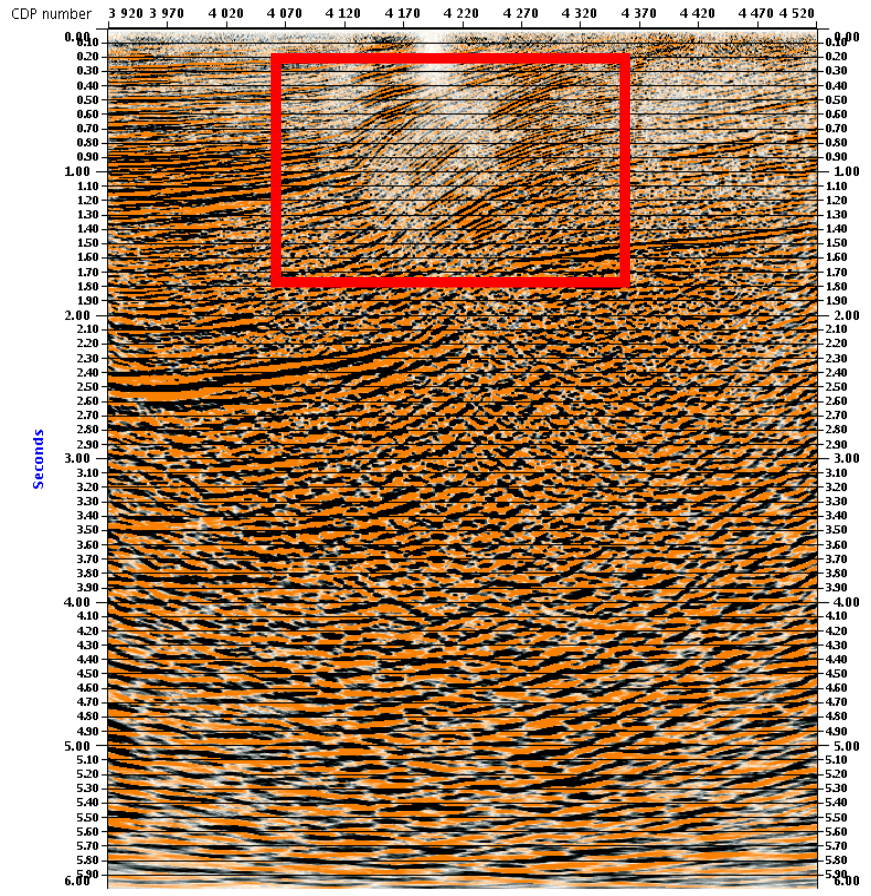

Gambar 5. Hasil stacking migrasi kirhhoff dip $65^{0}$

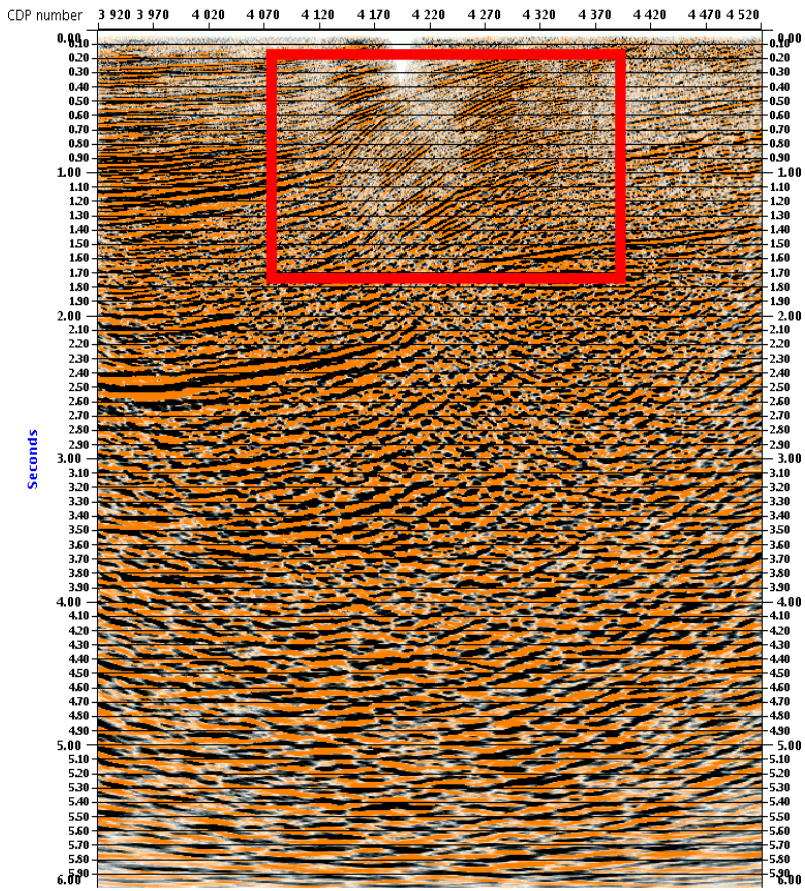

Gambar 6. Hasil stacking migrasi fx dip $65^{0}$ 


\section{Kesimpulan}

Kesimpulan yang dapat diambil dari penelitian ini yaitu, Terdapat perbedaan hasil konstruksi pada teknik migrasi pre stack time migration dengan metode kirchhoff dan metode $f x$ migration, yaitu pada metode kirchhoff terlihat bahwa kenampakan reflektor kurang jelas akan tetapi pencitraan reflektor terlihat lebih kontinyu. Sedangkan untuk metode $f x$ migration pencitraan bawah permukaan stack migrasi lebih terfokus pada titik reflektor, dan lebih baik digunakan pada kasus lapisan miring.

\section{Pengakuan}

Penulis ingin mengucapkan terima kasih kepada PT Elnusa khususnya divisi geosains data processing yang turut membantu dan mendukung dalam penyelesaian penelitian ini.

\section{Daftar Pustaka}

[1] Sismanto,. Seri Kegiatan Seismik Eksplorasi Modul 2 Pengolahan Data Seismik. Yogyakarta: Laboratorium Geofisika Fakultas MIPA Universitas Gadjah Mada. 1996

[2] Yilmaz, Ozdogan.. Seismik data processing, investigation ini Geophysics vol.1, Society of
Exploration Geophysics. Tusla, Oklahoma. 1989

[3] Telford, M.W., Geldart, L.P., Sheriff, R.E, Keys,D.A., Applied Geophysics,

- Cambridge University Press. New York . 1995

[4] Sheriff, R.E., and Geldart, L.P.,Exploration Seismology,Caambridge University Press,Cambridge. 1995

[5] Yilmaz 0. Seismic Data Analysis Processing, Inversion, and Interpretation of Seismic Data Volume 1. Society of Exploration Geophysics . Tulsa (US). 2001

[6] Sukmana, A., Kamalullah., Ardii, Dwi ., Migrasi Kirchhoff Pada Data Seismik Refleksi 2D. Jakarta. 2014

[7] Claerbout, , Seismik Migration : Imaging of Acoustic Energy By The Wave Field Extrapolation A Theoritical Aspec, Elsevier, Amsterdam. 1985

[8] Hutabarat, R.G. Integrasi Inversi Seismik dengan Atribut Amplitudo Seismik untuk Memetakan Distribusi Reservoar pada Lapangan Blackfoot. Jakarta. Universitas Indonesia. 2009 